\title{
Ensuring innovation competence in companies in emerging markets through the introduction of new quality methods
}

M. Thie ${ }^{1}$, L. Grotrian-Pahl ${ }^{1}$, G. Dias da Cunha ${ }^{2}$, J. L. Duarte Ribeiro $^{2}$, K. Narashiman ${ }^{3}$

${ }^{1}$ ATB Institute for Applied Systems Technology Bremen GmbH Wiener Str. 1, 28359 Bremen, Germany

Tel: +49421220920

Fax: +494212209210

e-mail:thie@atb-bremen.de

${ }^{2}$ Universidade Federal do Rio Grande do Sul, Engenharia de Produção, Brazil

Tel: +55513164005

Fax: +55513164007

ę-mail: gcunha@vortex.ufrgs.br

3 Anna University, AU-TVS Centre for Quality Management,

Chennai-600 025 Tamilnadu, India

Tel: +91 $442352047,+91442352047$

e-mail:autvscqm@annauniv.edu

\begin{abstract}
This paper presents the actual situation on quality methods in emerging countries. Brazil and India are typical examples of such countries. It includes an overview of the actual situation in these countries w.r.t. quality, the presentation of an approach to introduce such methods and a discussion on the results achieved.
\end{abstract}

Keywords

quality management, SMEs, emerging markets, IT support 


\section{INTRODUCTION}

In order to be able to compete with companies around the world and to face the challenge of globalisation and the new structure of markets, companies in emerging countries such as Brazil, Argentina, and India are now forced to improve their products and processes. Up to now companies, especially small and mediumsized enterprises (SMEs), have been mainly active on local markets, where it has been easier to sell their products, even if the operation and quality was not worldclass.

In order to maintain or better yet strengthen their position on the market, these SMEs have to improve their products and processes w.r.t. quality and productivity. This goal can be achieved through the introduction of management methods such as Lean Production or Total Quality Management. These methods have been applied by several companies throughout the world and also by large companies in these countries. Methods and procedures are necessary to assist companies, especially SMEs, in reaching world-class quality.

This paper presents a method for the efficient introduction of quality management systems (QM-systems) into the SMEs of emerging countries. The emphasis in this paper is put upon the actual situation of QM-systems in the countries Brazil and India and how such systems can be introduced into the SMEs of these countries.

\section{QUALITY MANAGEMENT SYSTEMS IN EMERGING MARKETS}

\subsection{Actual situation in Brazil}

Brazil is one of the world's top ten economies which has experienced an extreme transformation within the last decade. According to Miguel et al, 1997, Brazil has begun to deregulate and liberalize its economy, tearing down trade barriers and attempting to get a grip on public finance and inflation. Additionally, in 1994, the Brazilian government launched the Brazilian Program for Quality and Productivity which contributed to radical changes in the enterprises faced with the complex situation regarding the global market. This program suggested mechanisms to improve the quality of products and management in order to achieve international levels. For instance, there are many certification bodies currently auditing Brazilian companies so that the number of qualified Brazilian companies has increased.

According to Marinho \& Amato Neto, 1997, the establishment of the global market led to fundamental changes in Brazilian companies. They were confronted with a new reality, having to compete with products from the European Community, NAFTA, Japan, and mainly the "aggressive Asiatic Tigers". In order to be able to survive in this new scenario, the Brazilian industry had to adopt a series of measures that were more open and competitive and characteristic of the new economic global order. Initially, companies preferentially put their emphasis on eliminating production inefficiencies, reducing costs and establishing more stable 
relationships with business partners. Thus, due to the changes imposed by the globalization of the economy, Brazilian companies have experienced a transition period, passing from an economy with substantial interference to an economy where the dynamic core is based on quality, productivity and competitiveness that follow international standards.

This transition period is marked by the loss of old beliefs, caused by the collapse of organizational models that had been supporting the management style which was well accepted during the last century. This was represented by the old paradigm characterized by predominantly huge vertical productive units, in general, presenting highly hierarchical and complex administrative structures. The Brazilian companies are now facing a transition to a new paradigm, where the competitive strategy is based on diversification and flexibility. As a consequence, Brazilian companies are striving to achieve ISO 9000 certification and making substantial efforts to develop quality in order to have a competitive advantage (Marinho \& Amato Neto, 1997). Small and medium-sized companies have been reporting on the difficulties they have encountered associated with the implementation of QMsystems. Therefore, an approach to support such companies is an absolute necessity.

\subsection{Actual situation in India}

India, especially the area of Chennai (Madras), has become the "Detroit" of South and South East Asia where a vast number of subsidiaries of multinational automobile companies are operating. Pre-liberalisation government policies focussed on a number of socialistic patterns of development including, for example, the restriction of the automobile sector, a one time import of technology, the requirement of outsourcing, small volumes, strict segmentation etc. The increasing vehicular population and export potential will, however, have a sizeable positive impact on the economy.

The changing scenario has resulted in challenges for various Indian companies with respect to investment, technology, re-organisation and quality. There has been a paradigm shift in the practices regarding customer orientation. When taking into account the historic perspective, a long product life cycle, low expectations, price sensitive policies and the use of local mechanics for repair work and maintenance etc. were required. However, the newly focused paradigm looks for the use of general purpose machine tools and diverse original equipment manufacturing customers. Price and delivery have become driving forces together with low price after market requirements etc. The philosophy of manufacturers was one of strong vertical integration, critical components and in-house system assembly based, furthermore, on the belief in a large vendor base and a number of in-house developments etc.

Large companies or joint ventures normally have their own potential to be able to change the methods of working. A lot of them have already introduced modern technologies and management methods. However, most SMEs are still working in the traditional manner as they have done in the past. Due to limited experience 
with such management methods, it is very difficult for them to independently introduce an efficient management system.

\section{TIME AND COST EFFICIENT NETWORK APPROACH BQM}

Bremen's Quality Management Model (BQM) was developed by means of a regional initiative for SMEs in northern Germany. The model integrates organisational, system technical and methodical elements into an overall concept for the time and cost efficient introduction of effective QM-systems. The essential goal is self-support which enables enterprises to independently design, introduce and maintain an effective company specific QM system in the future. The basic components of $\mathrm{BQM}$ are as follows (Figure ):

- Clearly structured Project Phases

The process of the introduction of a QM-system is structured into project phases with defined results.

- Group Concept

The main support to companies is carried out during group workshops. This enables costs to be shared by 8-10 companies and the motivation for each member is higher due to group work and discussion.

- Integrated Training

The companies are always trained on the topics necessary for the actual tasks. Subsequently the tasks are executed and verified by the consultants to give them further support.

- Support by the Software System CATISO

A special software tool is used for the analysis, documentation and long-term maintenance of the QM-system.

- Network of Experts

Support is delivered through a network of experts making a higher level of expertise available for the different topics. 


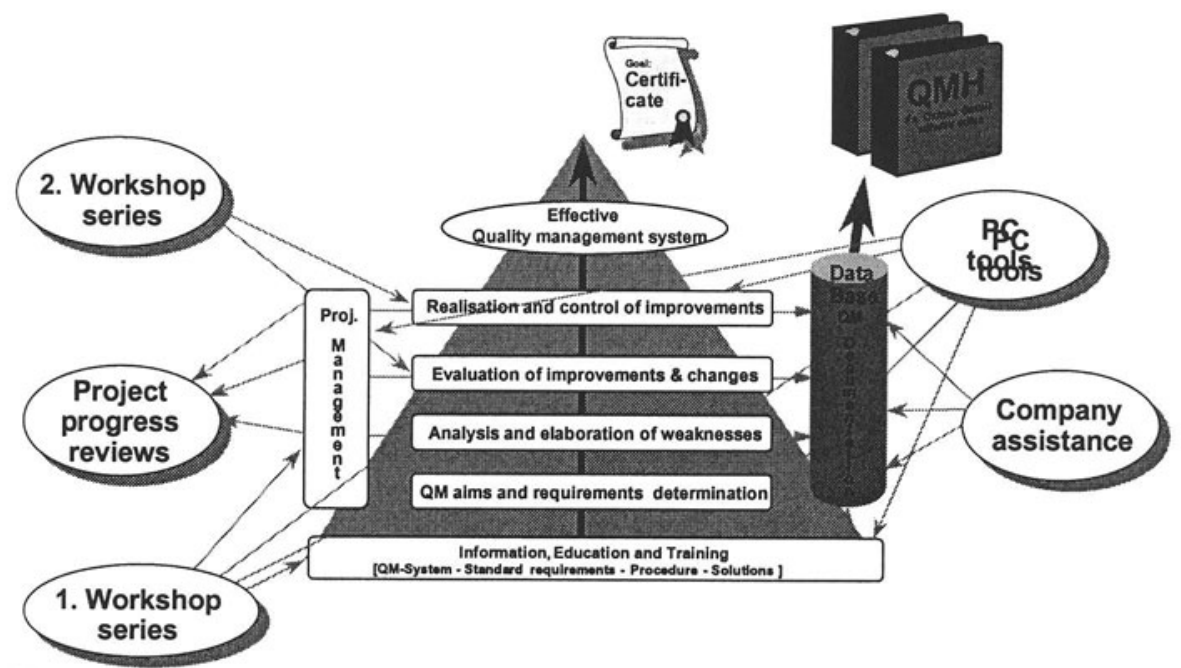

Figure 1: Structure of the BQM model (Badgasarian \& Thie, 1996)

In order to be able to transfer such a model to improve the innovative competence of companies, a dissemination model has been developed taking into account the advantages of using locally oriented consultants and with the effective combination of network harmonisation on a world wide level (Figure ). The advantages of local consultants for SMEs are obvious, for e.g.:

- Successful consultancies for SME's are based on personal trust; this can be more easily realised at the local level.

- Language and cultural problems do not present a local barrier.

- Minimisation of consultancy costs through the reduction of travelling costs.

- Local consultants know the companies and local problems best.

Therefore, the transfer of the model is based on local networks organised around the nodes which include local consultants. The main objectives of such a local network are:

- Supporting SME's on an individual basis in order to introduce advanced organisational structures and technologies, in addition to seminars and training courses being offered.

- Initiating experience exchanges between SME's and increasing co-operation awareness.

- Introducing a cost efficient approach for the individual support of SME's. 


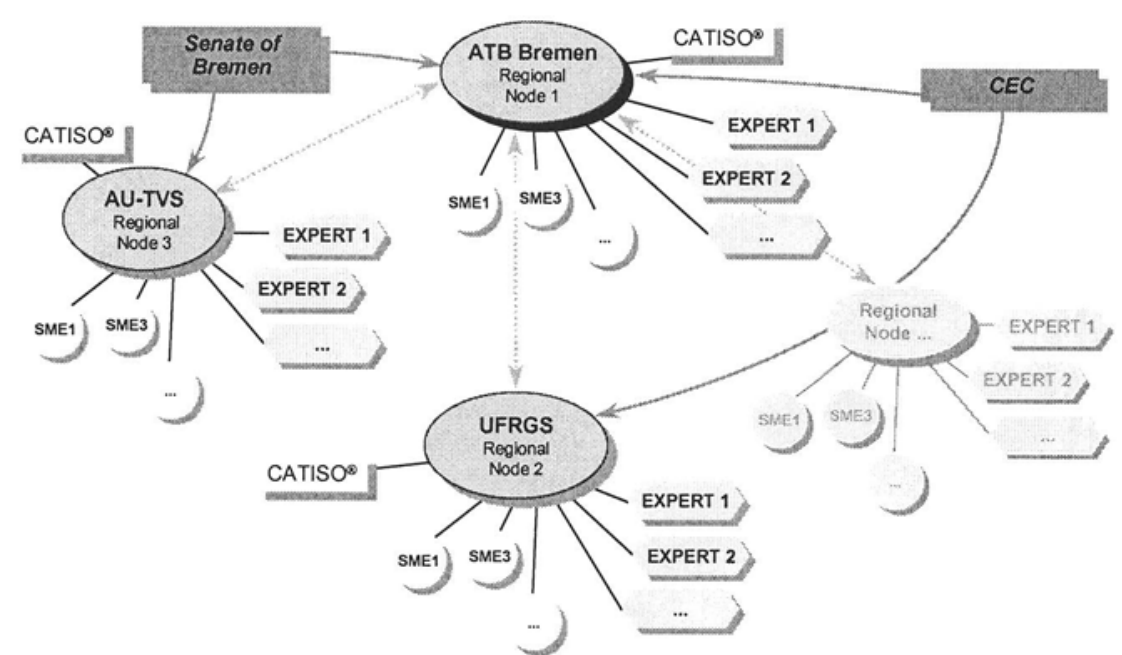

Figure 2: Model of network co-operation

In order to gain the advantages of a world-wide harmonisation of activities, the transfer of such models must include strong networking between the nodes. By means of this the following advantages can be achieved:

- Elaborated and successfully applied concepts for SMEs are disseminated throughout the world, most especially to emerging countries.

- Consultants of the different network nodes apply the same or similar methodology and tools and can be improved based on world-wide experience.

\section{EXPERIENCE IN THE INTRODUCTION OF QM-SYSTEMS}

The adaptation and transfer of such a method to introduce QM-systems was done in two different manners:

- Brazil: In order to concentrate on further adaptations and extensions of the BQM model, especially with respect to specific quality methods, the model was first executed for one pilot company.

- India: In order to verify the possibility of transferring such group models to emerging countries, the model was applied straightforward to a group of companies.

\subsection{Experience acquired applying the model in Brazil}

A company producing metal tanks was selected as the pilot-company for the attempt to implement the aforementioned model. It was intended that results arising from this attempt would guide foreseen actions regarding other Brazilian companies, making this company a demonstrator of the implementation approach. A typical example of a local SME, the company belongs to a family whose 
members perform as top managers. This results in a situation where a few people take responsibility for several tasks simultaneously. The company's objective in implementing an effective QM-system is to achieve higher standards of competitiveness.

Due to the specific situation in Brazil the following points can be stated:

- Without specific training the company's staff is not able to implement new methodologies (such as QM-systems) on their own.

- The educational level of employees are not adequate enough, making it extremely difficult for them to apply the new methodologies/technologies.

- Companies can get funding to purchase new methodologies/technologies but they refuse to do so unless they can count on skilled staff to implement and operate these new methodologies/technologies.

This means that companies will only be able to introduce such methodologies/technologies if their people can be adequately trained to apply these. This requires additional training on different topics, especially on quality fundamentals.

Nevertheless, the results acquired so far show that the implementation of the BQM Method at the pilot-company has contributed to modifying the company profile and its concerns related to quality problems. Although implementation has not yet been completed, some reasonable modifications have already been made in the manner in which the company operates at the moment (mostly with respect to its internal procedures).

\subsection{Experience using the model in India}

In order to verify the developed/adapted model, a network of 10 enterprises (mainly small scale enterprises which produce components for automotive suppliers, but also a service company) was established to introduce QM-systems. These organisations were strongly management driven, i.e. orientation was towards top management - the entrepreneur. This approach, however, is constrained if the second in command in the organisational structure is weak resulting in delays in the absence of the entrepreneur, non-transparency of the organisation etc. In order to rectify this situation, the BQM model was applied. Efforts were strengthened by the present industrial customer demand for transparent systems.

The enterprises are accustomed to have individual consultants which conveys them with the feeling that they will continue to maintain their isolated system approach. Hence, the focus was placed on offering individual counselling, documentation and implementation to the factory supported by network learning during the selected training programmes. This network learning approach helped the enterprises to gain far more knowledge than could be generated by a single company.

The following significant changes were necessary due to the specific situation in India and executed while implementing the model: 
- Consultants were deployed to the enterprises. Once confidence is established in the person, confidence in the system follows.

- Extra training in MS Office was executed since staff members were not familiar with it.

- Information in the templates and given documents was updated since a specific English terminology is used for some topics in India.

The BQM Model was very comprehensive and effective. After only 9 months, 2 companies have already completed their adequacy audit with the certifying body. The remaining 8 companies will follow. Additionally, several improvements in quality and productivity have already been achieved. Due to the success of the model it can be expected that subsequent networks will be established.

\section{CONCLUSION}

The paper presents a method to improve the competitive position of companies, especially SMEs in emerging countries. The adapted method is based on a selfhelp approach to introduce modern management systems in a network of companies. Initial results have shown that it is working successfully and due to the similar situation in these countries, it was necessary to execute similar adaptations to the model. The achieved experiences will be evaluated further in order to establish an even stronger world-wide network between different network nodes for the exchange of methods and tools to support SMEs. It is also planned to use such networks to promote the exchange of further methods with respect to Best Practice.

\section{ACKNOWLEDGEMENTS}

The work here described received support from the European Community through the INCO project ProSME and the State of Bremen through the project CQM.

\section{REFERENCES}

Bagdasarian, P.; Thie, M. (1996): Mit Staates Hilfe. Qualität und Zuverlässigkeit, Hanser Verlag, 2, 180-183

Marinho, B.L. \& Amato Neto, B. (1997) - The need for quality management of suppliers in the global market. Proceedings of the XVII National Meeting on Industrial Engineering (in CD-ROM). Gramado, Brazil (in Portuguese).

Miguel, P.C., Weidmann, A., Schutzer, K. \& Abackerly, A. (1997) - A pilot study on industrial quality systems. Proceedings of the XVII National Meeting on Industrial Engineering (in CD-ROM). Gramado, Brazil. 


\section{BIOGRAPHY}

Michael Thie studied Mechanical Engineering at the University of Hannover. Since 1993 he has been working at ATB Institute for Applied System Technology Bremen $\mathrm{GmbH}$. His key areas of activity are quality management, quality methods and techniques, process optimisation and the introduction of IT-Systems. Since 1998 he has been responsible for the area quality management.

Liebhild Grotrian-Pahl studied mathematics, biology and physical education in Braunschweig and was a teacher from 1978 to 1990 . In 1995 she completed her studies in Systems Analysis at the school of engineering in Bremerhaven. Since 1995 she has been working for ATB Institute for Applied System Technology Bremen $\mathrm{GmbH}$ in the area of quality management.

Gilberto Dias da Cunha graduated in Mechanical Engineering (Federal University of Rio Grande do Sul, 1985). Doctoral degree: Mechanical Engineering - Industrial Technologies (New University of Lisbon, 1996). He is presently teaching at the Federal University and the Catholic University of Rio Grande do Sul giving courses in mechanical, automation and industrial Engineering.

José Luis Duarte Ribeiro is a full professor at the Industrial Engineering Graduate Program of the Federal University of Rio Grande do Sul and the Co-ordinator of LOPP - Laboratory for Optimization of Product and Process. He received his Ph.D. from the same university in 1989. His areas of interest are Statistical Process Control, Design of Experiments, Reliability, and Quality Function Deployment.

$\mathrm{K}$. Narashiman is a chemical engineer with a post graduate masters in management studies and a lead assessor. He has 14 years of experience in industry and at the university. He heads the Anna University TVS centre for quality management which develops quality skills among students and practising engineers. 